Article

\title{
$N, N$-Dimethylformamide (DMF) Usage in Epoxy/Graphene Nanocomposites: Problems Associated with Reaggregation
}

\author{
Jiacheng Wei, Mohd Shahneel Saharudin, Thuc Vo and Fawad Inam * \\ Faculty of Engineering and Environment, Department of Mechanical and Construction Engineering, \\ Northumbria University, Newcastle upon Tyne NE1 8ST, UK; jiacheng.wei@northumbria.ac.uk (J.W.); \\ mohd.saharudin@northumbria.ac.uk (M.S.S.); thuc.vo@northumbria.ac.uk (T.V.) \\ * Correspondence: fawad.inam@northumbria.ac.uk; Tel.: +44-191-227-3741 \\ Academic Editor: Alexander Böker \\ Received: 21 April 2017; Accepted: 24 May 2017; Published: 27 May 2017
}

\begin{abstract}
DMF is one the most commonly-used solvents for preparing graphene nanocomposites. Various processing variables for DMF are being used for the preparation of epoxy/graphene nanocomposites. Whilst the emphasis of all of these reported studies are on the improvements in mechanical, and other properties, of the epoxy/graphene nanocomposites, there is no study investigating how DMF affects the processing and how it is associated with the final properties of the nanocomposites. In this work, different dosages of DMF have been used to prepare nanocomposites. Mechanical testing, X-ray diffraction (XRD), dynamic mechanical analysis (DMA), thermogravimetric analysis (TGA), and scanning electron microscopy (SEM) have been used to analyze the effectiveness of DMF dosage on the properties of processed nanocomposites. Larger dosages of DMF are not always ideal for dispersing graphene as it promotes reaggregation of graphene during the processing.
\end{abstract}

Keywords: $\mathrm{N}, \mathrm{N}$-dimethylformamide (DMF); epoxy; graphene; reaggregation; nanocomposites

\section{Introduction}

Since its discovery in 2004 [1], graphene has rapidly gained both academic and industrial interest because of its outstanding properties, such as high surface to volume ratio, high aspect ratio, extremely low electrical resistivity, high thermal conductivity, and high mechanical strength and modulus [2]. These fascinating properties have attracted extensive research in recent years with ever-increasing scientific and technological impetus.

Epoxy is a widely used thermoset material due to its superior mechanical properties, thermal stability, solvent resistance, and ease of processing [3]. Applications of epoxy and its nanocomposites include aerospace, automotive, marine, sports materials, construction, structures, electrical and electronic systems, biomedical devices, thermal management systems, adhesives, paints, coatings, industrial tooling, and other general consumer products [4]. Its versatile nature makes it a good candidate to replace many conventional materials, for instance, epoxy-based materials have replaced woods in the majority of boats and various sports goods.

For epoxy/graphene nanocomposites, graphene can significantly improve the physical and chemical properties of the matrix at extremely low loadings [5], and this enhancement could only be achieved when graphene is homogeneously dispersed in the matrix. The uniformly-dispersed graphene could share external stress to avoid stress concentration and impede crack propagation, which leads to the improvements in the mechanical properties. On the contrary, poorly-dispersed graphene acts as stress raiser and causes stress concentration, resulting in the deterioration of the mechanical properties [5]. 
The exploration of property enhancements of epoxy/graphene nanocomposites is rapidly advancing. However, in practical terms, graphene is not suitable to disperse in epoxy just by simple mixing, as graphene tends to reaggregate in the matrix due to the strong van der Waals force even after homogenisation. Dispersing them in polymer resin with relatively high viscosity is difficult. Therefore, using solvents as dispersing media has been widely accepted and regarded as the simplest method to distribute isolated graphene homogeneously in the nanocomposite materials.

For example, in some studies [6-13], graphene was dispersed in acetone and improvements in the final properties of the nanocomposites were reported with $1 \mathrm{~g} / \mathrm{L}$ concentration of graphene. In some studies [14-25], graphene was dispersed in water, ethanol, tetrahydrofuran (THF), dichloromethane (DCM), and $N, N$-dimethylformamide (DMF) at $1 \mathrm{~g} / \mathrm{L}$, with remarkable improvement in the final properties. Dispersal of graphene in DMF, ethanol, and acetone have even been demonstrated at different concentrations, such as $1 \mathrm{~g} / 2 \mathrm{~L}, 1 \mathrm{~g} / 3 \mathrm{~L}$, or $1 \mathrm{~g} / 10 \mathrm{~L}$ [26-35]. For some other studies, solvents with unknown concentrations were used. For example, some reports [36,37] reported using DMF in the processing of epoxy/graphene nanocomposites and the final materials showed enhanced mechanical properties and resistance to fatigue crack growth. Some other articles [38-40] reported the usage of ethanol and the nanocomposites showed improved load transfer efficiency, as well as an improved glass transition temperature. Other solvents, like isopropanol [41,42], THF [43,44], butanone [45,46], acetone [47,48], and dichloromethane [49], have also been reported in the processing of epoxy/graphene nanocomposites. However, in all of these studies, the dosage of solvents had not been specified. Therefore, these analyses cannot be references for the usage of solvents in epoxy/graphene nanocomposites preparation. The dispersion effectiveness of popular solvents was reported by Shih et al. [50] using computational analyses of NMP $=$ DMSO $>$ DMF $>$ GBL $>$ water. However, there were no comments on the optimization of processing variables (e.g., dosage of solvent). To date, there has been no research publication addressing the effects of solvent volume on the properties of the epoxy/graphene nanocomposites. This study, therefore, examines the usage of DMF solvent for the processing of epoxy/graphene nanocomposites.

\section{Materials and Methods}

The epoxy matrix used in this study consists of EPOPHENTM EL5 bisphenol A based liquid epoxy (EP) and EPOPHENTM EHA57 diamine hardener (HD), purchased from Polyfibre UK Ltd. (Birmingham, UK) This epoxy system is a multi-purpose resin offering good all-round properties with the epoxy group content of $4.76-5.25 \mathrm{~mol} / \mathrm{kg}$. The viscosities of the liquid epoxy and hardener at room temperature are $12,000-15,000$ and $45 \mathrm{cps}$, respectively. To prepare the epoxy material (EP + HD), 100 parts by weight of liquid epoxy were mixed to 50 parts by weight of hardener. Graphene nanoplates were purchased from Graphene Laboratories Inc. (Calverton, NY, USA) (product name: AO-3). The graphene nanoplatelets, according to the manufacture's technical datasheet, have a specific surface area of $80 \mathrm{~m}^{2} / \mathrm{g}$, the average lateral size and thickness are $4.5 \mu \mathrm{m}$ and $12 \mathrm{~nm}$, respectively. Figure 1 shows the SEM image of graphene nanoplatelets. DMF used in this work was purchased from Sigma-Aldrich (Sigma-Aldrich Company Ltd., Gillingham, UK) with a purity of $99.9 \%$.

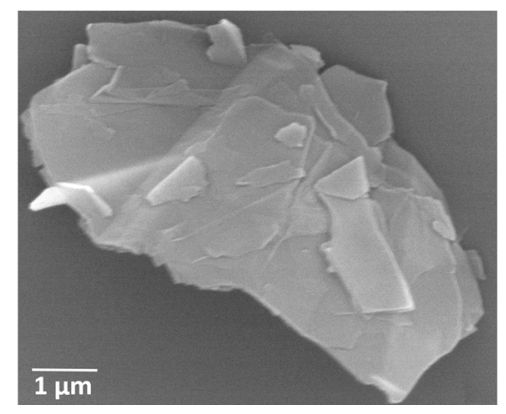

Figure 1. SEM image of a graphene nanoplatelet. 
Five sets of nanocomposites filled with $0.3 \mathrm{wt} \%$ graphene were prepared. One set of samples was prepared as a reference using neat epoxy only, marked as G-0.3. Another four sets were prepared with different dosages of DMF.

To understand the relationship among solvent dosage, graphene dispersion state, and the properties of the nanocomposites, $0.3 \mathrm{wt} \%$ epoxy/graphene nanocomposites were prepared by using different dosages of DMF. The dosages prepared were 100, 300, 500, and $1500 \mathrm{~mL}$. Graphene $(0.45 \mathrm{~g})$ was first dispersed in a specified dosage of $\operatorname{DMF}(100,300,500$, and $1500 \mathrm{~mL}$, respectively, marked as D-100, D-300, D-500, and D-1500, accordingly) and bath sonicated for $0.5 \mathrm{~h}$. Epoxy monomer was then added to the dispersion and sonicated for another $0.5 \mathrm{~h}$. To remove the DMF solvent, the mixtures were heated to $150{ }^{\circ} \mathrm{C}$ with stirring. The mixture with $100 \mathrm{~mL}$ of DMF was only heated for $4 \mathrm{~h}$, the mixtures with 300 and $500 \mathrm{~mL}$ DMF were heated for $8 \mathrm{~h}$, and the mixture with $1500 \mathrm{~mL}$ DMF was heated for $16 \mathrm{~h}$ to evaporate the solvent. All mixtures were weighed to ensure full removal of DMF. The mixtures were then cooled to room temperature and the hardener was added with hand stirring for $5 \mathrm{~min}$, followed by $5 \mathrm{~min}$ bath sonication. Vacuum degassing was then carried out to remove the entrapped air bubbles. Subsequently, the mixtures were mold-cast and cured at room temperature for $6 \mathrm{~h}$, followed by $6 \mathrm{~h}$ post-curing at $80^{\circ} \mathrm{C}$. Figure 2 shows the schematics of the sample preparation.

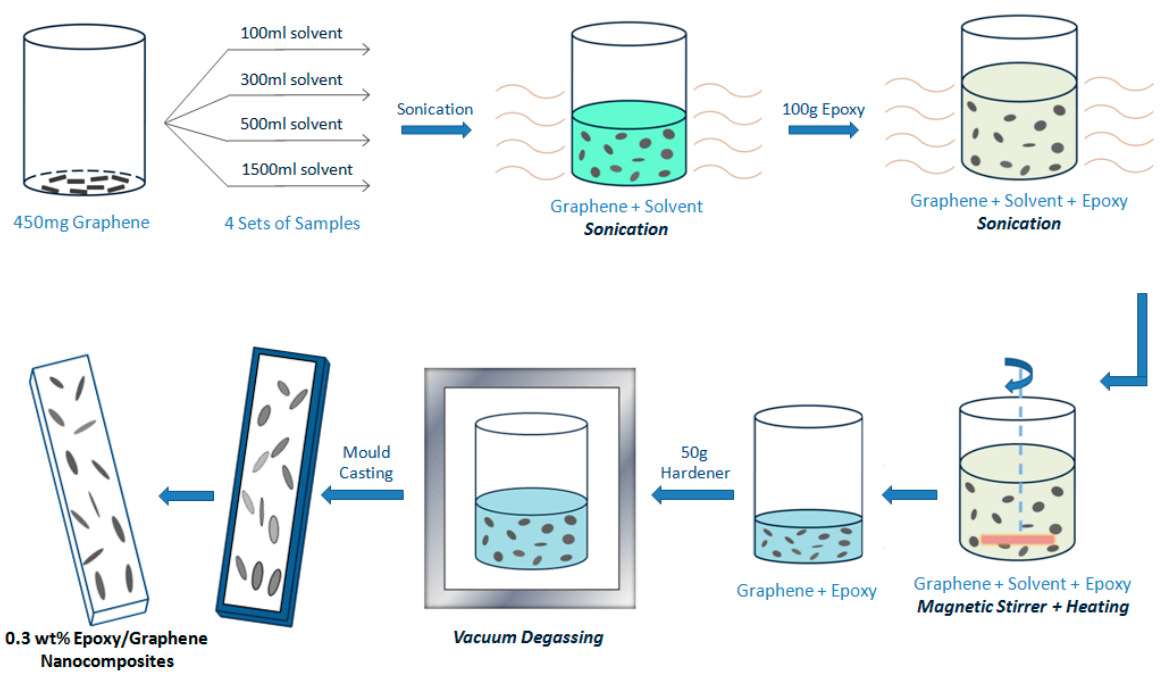

Figure 2. Schematic of the preparation of nanocomposites.

Tensile, three-point bend, and fracture toughness tests were conducted with a universal testing machine (Instron 3382, Instron Corporation, Norwood, MA, USA), and the crosshead speed was kept at $2 \mathrm{~mm} / \mathrm{min}$ for all tests. Tensile properties were measured according to ASTMD638 (Type V geometry). The three-point bend test was conducted according to ASTM D790 with specimen dimensions of $3 \mathrm{~mm}$ $\times 12.7 \mathrm{~mm} \times 48 \mathrm{~mm}$. A single-edge-notch three point bending (SEN-TPB) specimen was used to test mode-I fracture toughness $\left(K_{1 C}\right)$ according to ASTM D5045. The specimen dimensions were $3 \mathrm{~mm} \times$ $6 \mathrm{~mm} \times 36 \mathrm{~mm}$ with a crack length of $3 \mathrm{~mm}$. The notch was made at the middle of the sample and tapped to sharpen by a razor blade. The $K_{1 \mathrm{C}}$ was calculated using Equation (1):

$$
K_{1 C}=\frac{P_{\max } f\left(\frac{a}{w}\right)}{B W^{1 / 2}}
$$

where, $P_{\text {max }}$ is the maximum load of the load-displacement curve, $f(a / w)$ is constant related to the sample geometry and was calculated using Equation (2), $B$ is sample thickness ( $\mathrm{mm}$ ), $W$ is sample width $(\mathrm{mm})$, and $a$ is crack length (kept between 0.45 and $0.55 \mathrm{~W}$ ). The critical strain energy release rate $\left(G_{1 C}\right)$ was evaluated using Equation (3) where $E$ is the Young's modulus obtained from the tensile tests (MPa), and $v$ is the Poisson's ratio of the polymer, taken to be 0.35 . 


$$
\begin{gathered}
f\left(\frac{a}{w}\right)=\frac{\left[\left(2+\frac{a}{w}\right)\left\{0.0866+4.64\left(\frac{a}{w}\right)-13.32\left(\frac{a}{w}\right)^{2}+14.72\left(\frac{a}{w}\right)^{3}-5.6\left(\frac{a}{w}\right)^{4}\right\}\right]}{\left(1-\frac{a}{w}\right)^{3 / 2}} \\
G_{1 C}=\frac{K_{1 C^{2}\left(1-v^{2}\right)}}{E}
\end{gathered}
$$

A dynamic mechanical analyzer (DMA) (Model 8000, Perkin Elmer, Waltham, MA, USA) was used to determine the storage modulus $\left(E^{\prime}\right)$ and loss factor $\tan \delta$. All tests were conducted by using the temperature sweep method (temperature ramp from 30 to $150{ }^{\circ} \mathrm{C}$ at $5{ }^{\circ} \mathrm{C} / \mathrm{min}$ ) at a constant frequency of $1 \mathrm{~Hz}$. Thermogravimetric analysis (TGA) of the nanocomposites was carried out with a TA Instruments Q500 thermal analyzer (TA Instruments, New Castle, DE, USA). The temperature range was from room temperature to $600{ }^{\circ} \mathrm{C}$ at a ramp rate of $5{ }^{\circ} \mathrm{C} / \mathrm{min}$ under $\mathrm{N}_{2}$ atmosphere. The structure of the epoxy/graphene nanocomposites was examined using X-ray diffraction (XRD) carried out with a Siemens D-5000 diffractometer (Bruker Corporation, Coventry, UK) using a Cu K $\alpha$ radiation source $(\lambda=0.15406 \mathrm{~nm})$ with step size of $0.02^{\circ}$. Scanning electron microscopy (SEM) analysis was carried out using a FEI Quanta 200 microscope (FEI Corporation, Hillsboro, OR, USA) to examine the fracture surfaces of nanocomposites. The fractured surfaces were cut from the specimens and a layer of gold was applied using an Emscope sputter coater, model SC500A (Quorum Technologies Ltd., Laughton, UK). For tensile, flexural, fracture, and hardness tests, six specimens were tested for each set of conditions and mean values were then reported.

\section{Results and Discussion}

\subsection{Mechanical Properties of Nanocomposites}

Most work on epoxy/graphene nanocomposites aims at improving the mechanical properties of the nanocomposites, while the dispersion state of graphene, in return, affects the macroscopic properties of the matrix. Therefore, the mechanical properties of the nanocomposites have been tested and summarized in Figure 3.
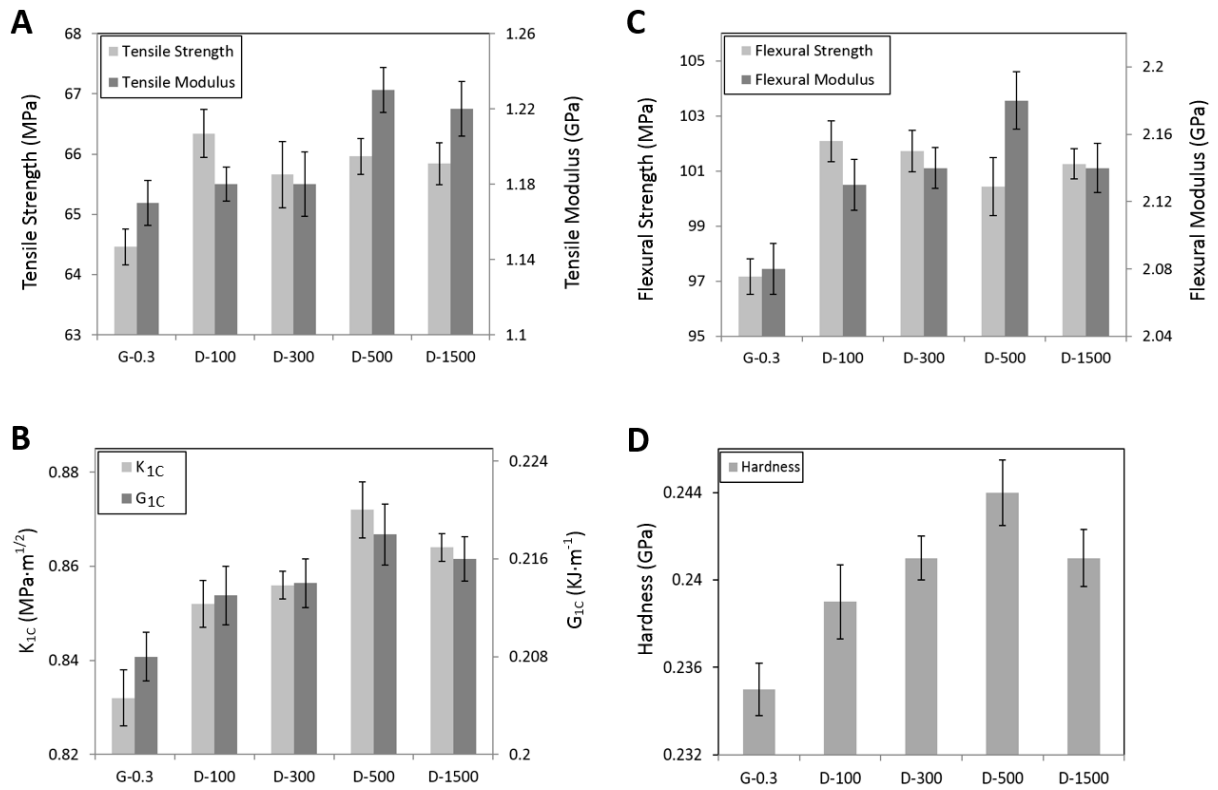

Figure 3. Mechanical properties of epoxy/graphene nanocomposites: (A) tensile properties; (B) flexural properties; (C) fracture properties; and (D) hardness. 
As can be seen from the figure, G-0.3 shows the lowest mechanical properties. Overall, the mechanical properties of the nanocomposites showed enhancements when DMF was used. For tensile strength and flexural strength, D-100 samples showed the highest values, whereas for tensile the modulus, flexural modulus, $K_{1 C}, G_{1 C}$, and hardness, D-500 samples showed the highest values. The general improvements of these properties are due to good distribution of graphene by using DMF. Uniformly-dispersed graphene could improve the energy-absorbing capacity of the material, restrict the epoxy chain mobility, and shorten the distance among cross-linking points, thus increasing the properties of the nanocomposites [5].

However, when too much solvent was used, e.g., $1500 \mathrm{~mL}$ DMF in this work, lower properties were observed in comparison with the samples prepared with less solvent, e.g., 100 or $500 \mathrm{~mL}$ DMF. This decrease can be associated with the reaggregation of the graphene, which occurred due to the large dosage of DMF used.

\subsection{TGA Test of Nanocomposites}

Thermal decomposition is one of the fundamental thermal properties and is critical for practical applications. Figure 4 shows the TGA curves of the nanocomposites in a nitrogen atmosphere. It can be seen that all samples have a similar two-stage weight loss, indicating that they have a similar thermal degradation mechanism. The first weight loss from 100 to $230^{\circ} \mathrm{C}$ was attributed to the decomposition of small molecules on the side chain. The second weight loss, occurring from 250 to $500{ }^{\circ} \mathrm{C}$, shows the decomposition of the main polymer chain.

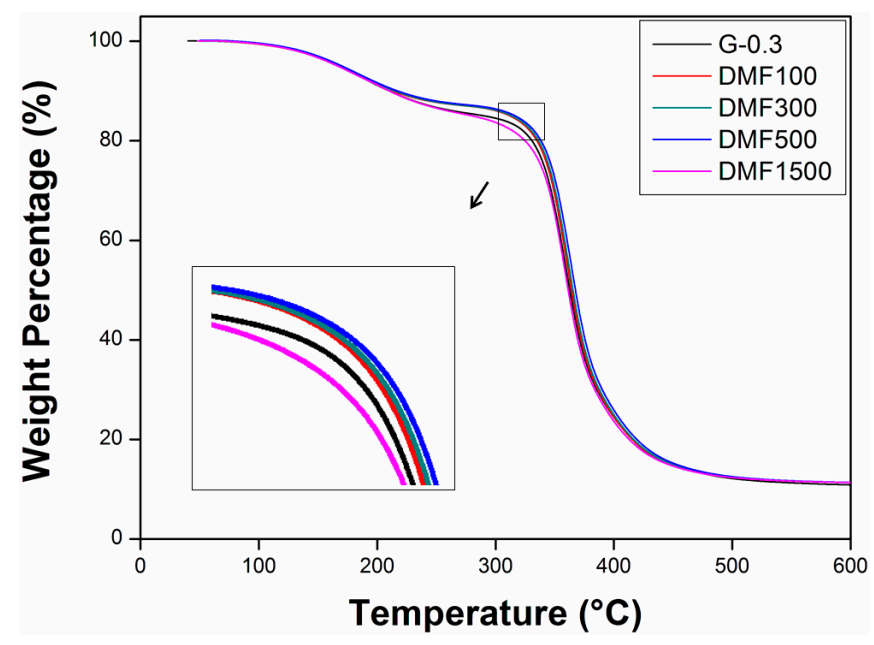

Figure 4. TGA curves of the nanocomposites.

As can be seen from the Figure 4, all D-100, D-300, and D-500 samples showed lower decomposition rates as compared to G-0.3 samples, which means D-100, D-300, and D-500 samples have higher thermal stabilities. The reason can be ascribed to the fact that graphene can increase the cross-linking density of the epoxy, and other thermoset polymers, as elaborated elsewhere [51-53], thus leading to higher thermal stability. In general, the increased dispersion of graphene in D-100, D-300, and D-500 samples resulted in a higher heat capacity of the nanocomposites. However, when too much solvent was used, e.g., $1500 \mathrm{~mL}$ DMF in this work, non-uniformly-dispersed graphene decreased the properties of nanocomposites; thus, D-1500 samples showed the highest decomposition rate under heating.

\subsection{DMA Results of Nanocomposites}

Figure 5A shows the storage modulus $\left(E^{\prime}\right)$ as a function of temperature for epoxy/graphene nanocomposites. As can be seen from the figure, the storage modulus of G-0.3 is $2.35 \mathrm{GPa}$. With the 
increasing dosage of DMF, D-100, D-300, and D-500 samples show increased storage moduli of 2.45, 2.52, and 2.60 GPa respectively. However, with the further increase of the DMF dosage, D-1500 shows a decreased storage modulus with the value of $2.31 \mathrm{GPa}$. This is the lowest value among all of the samples.
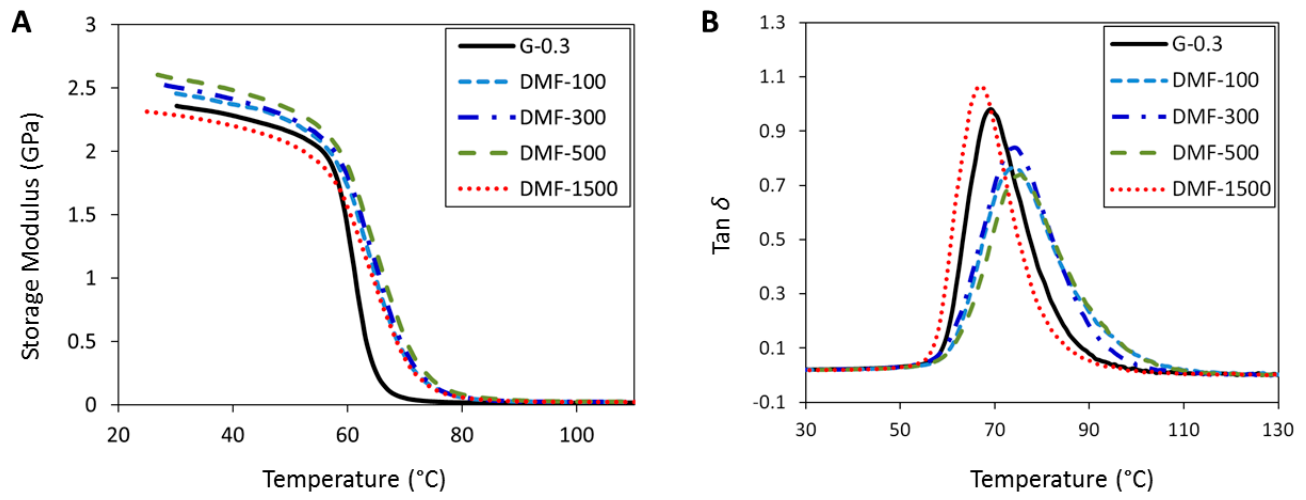

Figure 5. DMA results of nanocomposites: (A) storage modulus; and (B) $\tan \delta$.

The glass transition temperature $\left(T_{g}\right)$ characterizes the segmental motion of polymers and was taken as the temperature value at the peak of the $\tan \delta$ curves, as shown in Figure 5B. In the figure it can be seen that the $\tan \delta$ peak is observed at $69.28^{\circ} \mathrm{C}$ for nanocomposites prepared with no DMF and, for nanocomposites prepared with 100,300 , and $500 \mathrm{~mL} \mathrm{DMF}, T_{g}$ shifted to a higher temperature. This can be ascribed to the fact that the uniformly-dispersed graphene restricted molecular mobility of the epoxy matrix, thus leading to the increased $T_{g}$ values. Among all of these increments, $500 \mathrm{~mL}$ DMF-prepared nanocomposites showed the highest $T_{g}$ of $75.57^{\circ} \mathrm{C}$, which is more than $6{ }^{\circ} \mathrm{C}$ higher than that of G-0.3 samples, while a $5{ }^{\circ} \mathrm{C}$ increment in $T_{g}$ was observed for D-100 and D-300 samples. The reason for this improvement can be explained by the effect of graphene on the cross-linking structure of the nanocomposites. Generally, the cross-linking density means the concentration of cross-linked bonds per volume. As for a typical polymer nanocomposite, the higher the cross-linking density, the stronger the polymer chains bond to each other, therefore leading to a higher $T_{g}$ of the nanocomposites. However, samples prepared with $1500 \mathrm{~mL}$ DMF show the lowest $T_{g}$ value of $65.78^{\circ} \mathrm{C}$. The likely reason for this decrease is that graphene, in a liquid matrix, tends to reaggregate over time, especially in a low viscosity medium. As a larger dosage of DMF requires a longer time for complete evaporation, the reaggregation of graphene is more likely to occur. Comparing with the structures of well-dispersed epoxy/graphene nanocomposites, the non-uniformly-dispersed graphene decreased the $T_{g}$.

To summarize the mechanical properties, it has been described in the previous published research that due to the strong van der Waals force on dispersed graphene sheets, graphene tends to reaggregate in liquid matrix with the passage of time [54-56]. From the analysis (Figures 3-5) it can, therefore, be concluded that large dosage of DMF (e.g., D-1500) provides an ideal low viscous medium for graphene to re-agglomerate. It is also a time-consuming task to evaporate DMF completely; therefore, prevention of re-agglomeration with time can only be accomplished if minimal, but appropriate, dosages of DMF are used (e.g., 100 or $500 \mathrm{~mL}$ ), as evidenced in this work.

\subsection{SEM Images of Nanocomposites}

The fracture surfaces of nanocomposites were examined by SEM and are shown in Figure 6. For G-0.3 samples, as shown in Figure 6A, some poorly-dispersed graphene can be seen on the surface. This poorly-dispersed surface features a poor interfacial interaction between the matrix and graphene. It also shows the brittle nature of the material and poor resistance to crack initiation and propagation. Compared with G-0.3, the fracture surfaces of D-100, D-300, and D-500 samples are relatively more 
uniform, as shown in Figure 6B-D. The clear fracture patterns show the sheet/sheet delamination as the fracture mechanism for the nanocomposites, and reveals that the usage of appropriate amounts of DMF are able to generate a uniform dispersion of graphene. The uniformly-dispersed graphene in the matrix can form a continuous network, which can release stress concentration. Additionally, uniformly-dispersed graphene could bridge growing cracks, thus stabilizing and stopping the cracks from developing into larger and harmful cracks. This also enhances the properties of nanomaterials. However, for D-1500 samples, as shown in Figure 6E, graphene aggregates could still be seen on the fracture surface. These aggregates form defects in the nanocomposites, act to concentrate the stresses locally, and cause localized weakness, thus causing large cracks and decreasing the properties of the nanocomposites.
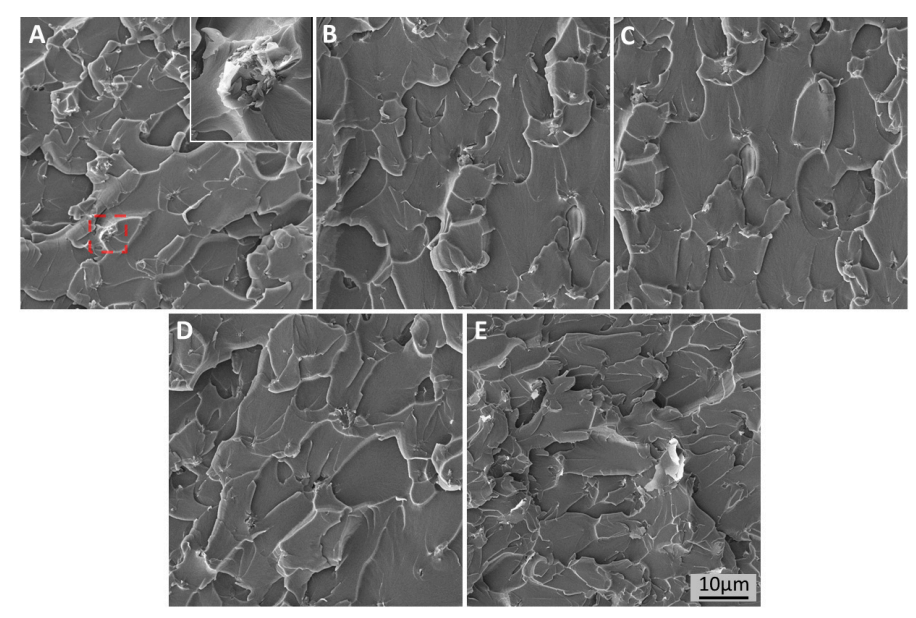

Figure 6. SEM images of fracture surfaces of (A) G-0.3; (B) D-100; (C) D-300; (D) D-500; and (E) D-1500.

\subsection{XRD Results of Nanocomposites}

Finally, XRD was used to characterize the structure of epoxy/graphene nanocomposites. As shown in Figure 7, all of the samples exhibit a wide diffraction from $11^{\circ}-28^{\circ}$, which is caused by the scattering of the $\mathrm{X}$-ray beam by cured epoxy molecules and shows the amorphous feature of the matrix. However, for samples prepared with $1500 \mathrm{~mL} \mathrm{DMF}$, there is a sharp shoulder peak of $2 \theta$ at $26.5^{\circ}$, which features the structure of graphite.

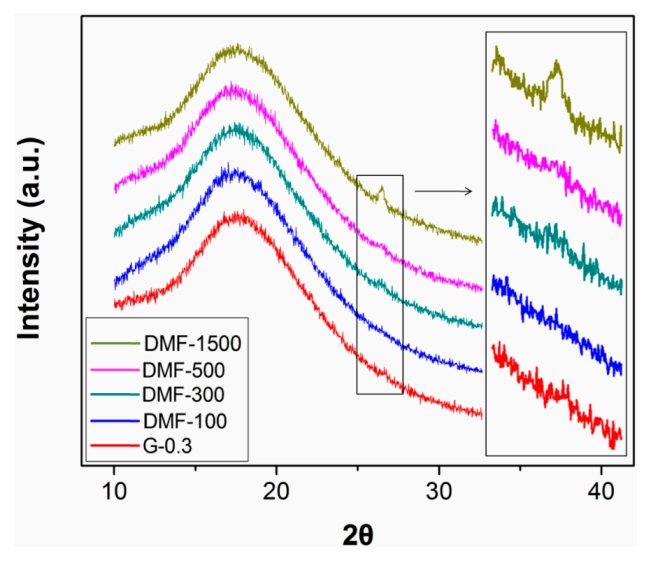

Figure 7. XRD patterns of nanocomposites.

This graphitic structure could only be caused by the agglomeration of graphene during processing. This result clearly shows that the use of a large dosage of DMF has induced reaggregation of graphene, which leads to the decrements in the properties. 
In summary, polar solvents, like DMF, are responsible for providing a low-viscosity medium, which is an ideal environment for fullerenes to agglomerate [53]. It is also widely understood that bonding (either physical or chemical) can be accelerated by increasing the temperature. While drying, higher temperatures are responsible for promoting agglomeration between graphene sheets. This results in the triggering of van der Waals forces on graphene surfaces in close proximity with each other, leading to agglomeration. In practical terms, larger dosages of solvent require longer times for complete evaporation. Therefore, it can be further concluded that the long processing time, higher temperatures, and low-viscosity solvents are responsible for the promotion of reagglomeration of graphene. This has also been confirmed by other publications [54-56] as well. For example, in one of our previous works [56], reaggreation of graphene (with the passage of time) in various liquids was confirmed via UV-VIS spectroscopy.

\section{Conclusions}

DMF was used to investigate the effects of solvent dosage on the preparation and properties of epoxy/graphene nanocomposites. This research provides guidelines for the usage of DMF solvents in the preparation of epoxy/graphene nanocomposites, and could also be a reference for other polymer composites where the use of solvents is required in the processing. Mechanical properties, TGA, DMA, SEM, and XRD were tested in this work. The results show that large dosage of solvents are responsible for decreasing the final properties of the nanocomposites. The long processing time, higher temperatures, and low viscosity of solvents are responsible for the promotion of the reagglomeration of graphene. These findings will have profound implications in nanocomposites manufacturing, as large amounts of solvents could be avoided from economic and health and safety perspectives. The processing time could be shortened causing less environmental pollution by reducing the amount evaporated solvents. These results help in optimisation and are having positive implications on the practical processing technology of nanocomposites. However, although the relationship between solvent dosage and the consequent processing of epoxy/graphene nanocomposites has been demonstrated here for the first time, it has not given the critical value for the best condition of dispersibility and processability. Therefore, more work needs to be conducted to fully understand the best usage of solvents.

Acknowledgments: The authors would like to thank the Department of Mechanical and Construction Engineering, Northumbria University for the provision of research facilities, without which the collection and analysis of relevant data was not possible.

Author Contributions: Jiacheng Wei conducted most of the lab work and wrote the manuscript. Mohd Shahneel Saharudin assisted in part of the experiments and testing. Thuc Vo and Fawad Inam supervised the project and gave research guidelines. All authors contributed to the revision and proofreading of the manuscript.

Conflicts of Interest: The authors declare no conflict of interest.

\section{References}

1. Novoselov, K.S.; Geim, A.K.; Morozov, S.V.; Jiang, D.; Zhang, Y.; Dubonos, S.V.; Grigorieva, I.V.; Firsov, A.A. Electric field effect in atomically thin carbon films. Science 2004, 306, 666-669. [CrossRef] [PubMed]

2. Geim, A.K.; Novoselov, K.S. The rise of graphene. Nat. Mater. 2007, 6, 183-191. [CrossRef] [PubMed]

3. Guadagno, L.; Raimondo, M.; Vittoria, V.; Vertuccio, L.; Naddeo, C.; Russo, S.; De Vivo, B.; Lamberti, P.; Spinelli, G.; Tucci, V. Development of epoxy mixtures for application in aeronautics and aerospace. RSC. Adv. 2014, 4, 15474. [CrossRef]

4. Inam, F. Epoxy-The hub for the most versatile polymer with exceptional combination of superlative features. Epoxy 2014, 1, 1-2. [CrossRef]

5. Wei, J.; Vo, T.; Inam, F. Epoxy/graphene nanocomposites-Processing and properties: A review. RSC. Adv. 2015, 5, 1351-1359. [CrossRef]

6. Rafiee, M.A.; Rafiee, J.; Srivastava, I.; Wang, Z.; Song, H.; Yu, Z.Z.; Koratkar, N. Fracture and fatigue in graphene nanocomposites. Small 2010, 6, 179-183. [CrossRef] [PubMed] 
7. Shen, X.J.; Liu, Y.; Xiao, H.M.; Feng, Q.P.; Yu, Z.Z.; Fu, S.Y. The reinforcing effect of graphene nanosheets on the cryogenic mechanical properties of epoxy resins. Compos. Sci. Technol. 2012, 72, 1581-1587. [CrossRef]

8. Galpaya, D.; Wang, M.; George, G.; Motta, N.; Waclawik, E.; Yan, C. Preparation of graphene oxide/epoxy nanocomposites with significantly improved mechanical properties. J. Appl. Phys. 2014, 116, 053518. [CrossRef]

9. Naebe, M.; Wang, J.; Amini, A.; Khayyam, H.; Hameed, N.; Li, L.H.; Chen, Y.; Fox, B. Mechanical property and structure of covalent functionalised graphene/epoxy nanocomposites. Sci. Rep. 2014, 4, 4375. [CrossRef] [PubMed]

10. Rafiee, M.A.; Rafiee, J.; Wang, Z.; Song, H.; Yu, Z.Z.; Koratkar, N. Enhanced mechanical properties of nanocomposites at low graphene content. ACS. Nano. 2009, 3, 3884-3890. [CrossRef] [PubMed]

11. Wang, X.; Jin, J.; Song, M. An investigation of the mechanism of graphene toughening epoxy. Carbon. 2013, 65, 324-333. [CrossRef]

12. Wang, X.; Xing, W.; Zhang, P.; Song, L.; Yang, H.; Hu, Y. Covalent functionalization of graphene with organosilane and its use as a reinforcement in epoxy composites. Compos. Sci. Technol. 2013, 65, 737-743. [CrossRef]

13. Gogoi, P.; Boruah, R.; Dolui, S.K. Jatropha curcas oil based alkyd/epoxy/graphene oxide (GO) bionanocomposites: Effect of GO on curing, mechanical and thermal properties. Prog. Org. Coat. 2015, 84, 128-135. [CrossRef]

14. Kim, K.S.; Jeon, I.Y.; Ahn, S.N.; Kwon, Y.D.; Baek, J.B. Edge-functionalized graphene-like platelets as a co-curing agent and a nanoscale additive to epoxy resin. J. Mater. Chem. 2011, 21, 7337. [CrossRef]

15. Yang, Y.; Rigdon, W.; Huang, X.; Li, X. Enhancing graphene reinforcing potential in composites by hydrogen passivation induced dispersion. Sci. Rep. 2013, 3, 2086. [CrossRef] [PubMed]

16. Meng, Q.; Jin, J.; Wang, R.; Kuan, H.C.; Ma, J.; Kawashima, N.; Michelmore, A.; Zhu, S.; Wang, C.H. Processable 3-nm thick graphene platelets of high electrical conductivity and their epoxy composites. Nanotechnology 2014, 25, 125707. [CrossRef] [PubMed]

17. Yousefi, N.; Lin, X.; Zheng, Q.; Shen, X.; Pothnis, J.R.; Jia, J.; Zussman, E.; Kim, J.K. Simultaneous in situ reduction, self-alignment and covalent bonding in graphene oxide/epoxy composites. Carbon 2013, 59, 406-417. [CrossRef]

18. Li, Y.; Umer, R.; Isakovic, A.; Samad, Y.A.; Zheng, L.; Liao, K. Synergistic toughening of epoxy with carbon nanotubes and graphene oxide for improved long-term performance. RSC. Adv. 2013, 3, 8849. [CrossRef]

19. Pu, X.; Zhang, H.B.; Li, X.; Gui, C.; Yu, Z.Z. Thermally conductive and electrically insulating epoxy nanocomposites with silica-coated graphene. RSC. Adv. 2014, 4, 15297. [CrossRef]

20. Li, Q.; Guo, Y.; Li, W.; Qiu, S.; Zhu, C.; Wei, X.; Chen, M.; Liu, C.; Liao, S.; Gong, Y.; Mishra, A.K. Ultrahigh thermal conductivity of assembled aligned multilayer graphene/epoxy composite. Chem. Mater. 2014, 26, 4459-4465. [CrossRef]

21. Ming, P.; Zhang, Y.; Bao, J.; Liu, G.; Li, Z.; Jiang, L.; Cheng, Q. Bioinspired highly electrically conductive graphene-epoxy layered composites. RSC. Adv. 2015, 5, 22283-22288. [CrossRef]

22. Wang, J.; Sun, Y.; Chen, W.; Wang, T.; Xu, R.; Wang, J. Enhanced microwave absorption performance of lightweight absorber based on reduced graphene oxide and Ag-coated hollow glass spheres/epoxy composite. J. Appl. Phys. 2015, 117, 154903. [CrossRef]

23. Wang, J.; Wang, J.; Xu, R.; Sun, Y.; Zhang, B.; Chen, W.; Wang, T.; Yang, S. Enhanced microwave absorption properties of epoxy composites reinforced with Fe50Ni50-functionalized graphene. J. Alloy. Compd. 2015, 653, 14-21. [CrossRef]

24. Wang, C.; Ge, H.; Liu, H.; Guo, S. Microstructure and properties of carbon fiber sized with pickering emulsion based on graphene oxide sheets and its composite with epoxy resin. J. Appl. Polym. Sci. 2015, 132. [CrossRef]

25. Umer, R.; Li, Y.; Dong, Y.; Haroosh, H.J.; Liao, K. The effect of graphene oxide (GO) nanoparticles on the processing of epoxy/glass fiber composites using resin infusion. J. Adv. Manuf. Tech. 2015, 81, 2183-2192. [CrossRef]

26. Li, Z.; Young, R.J.; Wang, R.; Yang, F.; Hao, L.; Jiao, W.; Liu, W. The role of functional groups on graphene oxide in epoxy nanocomposites. Polymer 2013, 54, 5821-5829. [CrossRef]

27. Liu, W.; Koh, K.L.; Lu, J.; Yang, L.; Phua, S.; Kong, J.; Chen, Z.; Lu, X. Simultaneous catalyzing and reinforcing effects of imidazole-functionalized graphene in anhydride-cured epoxies. J. Mater. Chem. 2012, 22, 18395. [CrossRef] 
28. Shen, X.J.; Pei, X.Q.; Fu, S.Y.; Friedrich, K. Significantly modified tribological performance of epoxy nanocomposites at very low graphene oxide content. Polymer 2013, 54, 1234-1242. [CrossRef]

29. Yang, H.; Shan, C.; Li, F.; Zhang, Q.; Han, D.; Niu, L. Convenient preparation of tunably loaded chemically converted graphene oxide/epoxy resin nanocomposites from graphene oxide sheets through two-phase extraction. J. Mater. Chem. 2009, 19, 8856. [CrossRef]

30. Wang, R.; Li, Z.; Liu, W.; Jiao, W.; Hao, L.; Yang, F. Attapulgite-graphene oxide hybrids as thermal and mechanical reinforcements for epoxy composites. Compos. Sci. Technol. 2013, 87, 29-35. [CrossRef]

31. Song, S.H.; Park, K.H.; Kim, B.H.; Choi, Y.W.; Jun, G.H.; Lee, D.J.; Kong, B.S.; Paik, K.W.; Jeon, S. Enhanced thermal conductivity of epoxy-graphene composites by using non-oxidized graphene flakes with non-covalent functionalization. Adv. Mater. 2013, 25, 732-737. [CrossRef] [PubMed]

32. Liu, F.; Guo, K. Reinforcing epoxy resin through covalent integration of functionalized graphene nanosheets. Adv. Technol. 2014, 25, 418-423. [CrossRef]

33. Liu, S.; Yan, H.; Fang, Z.; Wang, H. Effect of graphene nanosheets on morphology, thermal stability and flame retardancy of epoxy resin. Compos. Sci. Technol. 2014, 90, 40-47. [CrossRef]

34. Liu, S.; Yan, H.; Fang, Z.; Guo, Z.; Wang, H. Effect of graphene nanosheets and layered double hydroxides on the flame retardancy and thermal degradation of epoxy resin. RSC Adv. 2014, 4, 18652. [CrossRef]

35. Liu, F.; Wu, L.; Song, Y.; Xia, W.; Guo, K. Effect of molecular chain length on the properties of amine-functionalized graphene oxide nanosheets/epoxy resins nanocomposites. RSC. Adv. 2015, 5, 45987-45995. [CrossRef]

36. Galpaya, D.G.; Fernando, J.F.; Rintoul, L.; Motta, N.; Waclawik, E.R.; Yan, C.; George, G.A. The effect of graphene oxide and its oxidized debris on the cure chemistry and interphase structure of epoxy nanocomposites. Polymer 2015, 71, 122-134. [CrossRef]

37. Zanjani, J.S.M.; Okan, B.S.; Menceloglu, Y.Z.; Yildiz, M. Nano-engineered design and manufacturing of high-performance epoxy matrix composites with carbon fiber/selectively integrated graphene as multi-scale reinforcements. RSC. Adv. 2016, 6, 9495-9506. [CrossRef]

38. Wang, R.; Zhuo, D.; Weng, Z.; Wu, L.; Cheng, X.; Zhou, Y.; Wang, J.; Xuan, B. A novel nanosilica/graphene oxide hybrid and its flame retarding epoxy resin with simultaneously improved mechanical, thermal conductivity, and dielectric properties. J. Mater. Chem. A. 2015, 3, 9826-9836. [CrossRef]

39. Tan, Y.; Luo, H.; Zhang, H.; Zhou, X.; Peng, S. Lightweight graphene nanoplatelet/boron carbide composite with high EMI shielding effectiveness. AIP Adv. 2016, 6, 035208. [CrossRef]

40. Qiao, S.J.; Xu, X.N.; Qiu, Y.; Xiao, H.C.; Zhu, Y.F. Simultaneous reduction and functionalization of graphene oxide by 4-Hydrazinobenzenesulfonic acid for polymer nanocomposites. Nanomaterials 2016, 6, 29. [CrossRef] [PubMed]

41. Barletta, M.; Vesco, S.; Puopolo, M.; Tagliaferri, V. Graphene reinforced UV-curable epoxy resins: Design, manufacture and material performance. Prog. Org. Coat. 2016, 90, 414-424. [CrossRef]

42. Barletta, M.; Vesco, S.; Puopolo, M.; Tagliaferri, V. High performance composite coatings on plastics: UV-curable cycloaliphatic epoxy resins reinforced by graphene or graphene derivatives. Surf. Coat. Tech. 2015, 272, 322-336. [CrossRef]

43. Zong, P.; Fu, J.; Chen, L.; Yin, J.; Dong, X.; Yuan, S.; Shi, L.; Deng, W. Effect of aminopropylisobutyl polyhedral oligomeric silsesquioxane functionalized graphene on the thermal conductivity and electrical insulation properties of epoxy composites. RSC. Adv. 2016, 6, 10498-10506. [CrossRef]

44. Arooj, Y.; Zhao, Y.; Han, X.; Bao, T.; Wang, Y. Combined effect of graphene oxide and MWCNTs on microwave absorbing performance of epoxy composites. Polym. Adv. Technol. 2015, 26, 620-625. [CrossRef]

45. Wang, P.N.; Hsieh, T.H.; Chiang, C.L.; Shen, M.Y. Synergetic effects of mechanical properties on graphene nanoplatelet and multiwalled carbon nanotube hybrids reinforced epoxy/carbon fiber composites. J. Nanomater. 2015, 7. [CrossRef]

46. Huang, X.; Zhi, C.; Jiang, P. Toward effective synergetic effects from graphene nanoplatelets and carbon nanotubes on thermal conductivity of ultrahigh volume fraction nanocarbon epoxy composites. J. Phys. Chem. C 2012, 116, 23812-23820. [CrossRef]

47. Chang, H.P.; Liu, H.C.; Tan, C.S. Using supercritical $\mathrm{CO}_{2}$-assisted mixing to prepare graphene/carbon nanotube/epoxy nanocomposites. Polymer 2015, 75, 125-133. [CrossRef] 
48. Zha, J.W.; Zhu, T.X.; Wu, Y.H.; Wang, S.J.; Li, R.K.; Dang, Z.M. Tuning of thermal and dielectric properties for epoxy composites filled with electrospun alumina fibers and graphene nanoplatelets through hybridization. J. Mater. Chem. C 2015, 3, 7195-7202. [CrossRef]

49. Hou, G.; Gao, J.; Xie, J.; Li, B. Preparation and properties characterization of gallic acid epoxy resin/succinic anhydride bionanocomposites modified by green reduced graphene oxide. Soft Mater. 2016, 14, 27-37. [CrossRef]

50. Shih, C.J.; Lin, S.; Strano, M.S.; Blankschtein, D. Understanding the stabilization of liquid-phase-exfoliated graphene in polar solvents: molecular dynamics simulations and kinetic theory of colloid aggregation. J. Am. Chem. Soc. 2010, 132, 14638-14648. [CrossRef] [PubMed]

51. Saleem, H.; Edathil, A.; Ncube, T.; Pokhrel, J.; Khoori, S.; Abraham, A.; Mittal, V. Mechanical and thermal properties of thermoset-graphene nanocomposites. Macromol. Mater. Eng. 2006, 301, 231-259. [CrossRef]

52. Gordana, M.; Visakh, P.M. Rubber Nano Blends: Preparation, Characterization and Applications, 1st ed.; Springer: Basel, Switzerland, 2016; pp. 18-23.

53. Atif, R.; Inam, F. Reasons and remedies for the agglomeration of multilayered graphene and carbon nanotubes in polymers. Beilstein. J. Nanotech. 2016, 7, 1174-1196. [CrossRef] [PubMed]

54. Inam, F.; Peijs, T. Re-aggregation of carbon nanotubes in two-component epoxy system. J. Nanostruc. Polym. Nanocomp. 2006, 2, 87-95.

55. Lisunova, M.O.; Lebovka, N.I.; Melezhyk, O.V.; Boiko, Y.P. Stability of aqueous suspensions of nanotubes in the presence of nonionic surfactant. J. Colloid Interf. Sci. 2006, 299, 740-746. [CrossRef] [PubMed]

56. Wei, J.; Atif, R.; Vo, T.; Inam, F. Graphene nanoplatelets in epoxy system: dispersion, reaggregation, and mechanical properties of nanocomposites. J. Nanomater. 2015, 16. [CrossRef]

(C) 2017 by the authors. Licensee MDPI, Basel, Switzerland. This article is an open access article distributed under the terms and conditions of the Creative Commons Attribution (CC BY) license (http:/ / creativecommons.org/licenses/by/4.0/). 